\title{
O MOdelo Religioso e o Progresso Ético da Comunidade de MATEus na PeRspectiva de MAX SCHELER
}

\author{
THE RELIGIOUS MODEL AND THE ETHICAL PROGRESS OF THE \\ MATHEW'S COMMUNITY IN MAX SCHELER'S PERSPECTIVE
}

Newton Aquiles von Zuben $(*)$
Maiara Rúbia Miguel $\left({ }^{* *}\right)$

\begin{abstract}
RESUMO
Compreender a força de influência de um modelo em uma unidade social foi preocupação do filósofo Max Scheler. Em seus trabalhos fenomenológicos sobre a experiência ética, Scheler demonstrou a importância da presença de um modelo religioso. Com isso em mente, o objetivo deste trabalho, respaldado pelo método da correlação alinhado à análise fenomenológica scheleriana, é localizar o modelo religioso e compreender o modo como se entende a experiência ética do mundo da comunidade mateana, a partir de uma investigação do texto bíblico Sermão da Montanha, tendo como base o pensamento de Max Scheler. Em suma, este trabalho, ao correlacionar as duas realidades textuais, a saber, o texto bíblico e o fenomenológico, tenta responder à seguinte questão: Qual a importância de Jesus Cristo, enquanto modelo religioso, para o progresso ético da comunidade mateana?
\end{abstract}

PALAVRAS-ChAVE: Modelo religioso. Progresso ético. Jesus Cristo. Max Scheler.

\begin{abstract}
The strength of a model in a social unity was a subject that Max Scheler was worried about and tried to comprehend. In his phenomenological papers about ethical progress, he demonstrated the importance of a religious model presence. With that in mind, the mainly goal of this paper, according to the correlation method associated to a phenomenological analyses, is locate the religious model in a community, and understand the possible form to comprehend the ethic experience inside of mathean community world from the bible text The mountain speech, based on Max Scheler's thought. In short, this paper, correlating two texts realities: a bible text and a phenomenological text, aims to answer the question: What is the importance of Jesus Christ, as a religious model, towards the religious experience of the mathean community?
\end{abstract}

KEYWORDS: Religious model. Ethical progress. Jesus Christ. Max Scheler.

\section{INTRODUÇÃO}

O modelo e o líder são duas personalidades influentes dentro de uma unidade social. Primeiramente, verifica-se a presença do modelo e, em segundo lugar, a presença do líder. Para Max Scheler, o modelo é mais influente e importante, pois sua força de atuação carrega o valor encarnado em pessoa, e desse modo atua sobre o modo de agir de uma unidade social específica. Por

\footnotetext{
(*) Doutor em Filosofia - Université Catholique de Louvain - (1970) e professor titular do Programa de Pós-Graduação em Ciências da Religião da Pontifícia Universidade Católica de Campinas. E-mail: nzuben@puc-campinas.edu.br.

${ }^{(* *)}$ Doutoranda em Ciência da Religião pela Universidade Federal de Juiz de Fora e Mestra em Ciências da Religião pela Pontifícia Universidade Católica de Campinas. E-mail: maiara_miguel@yahoo.com.br.
} 
outro lado, o líder atua sobre a vontade, tendo plena consciência de sua responsabilidade. O modelo não precisa saber que é modelo - sequer precisa existir. Sobre o que vem a ser um modelo, Scheler, em seu livro Modelos $e$ Líderes, referência neste artigo, afirma: "O modelo é discreto, age e se transforma nas profundezas da alma de cada pessoa e de cada grupo humano, no íntimo de cada pessoa individual e de cada pessoa social" (SCHELER, 1998, p. 16). Já o líder, por sua vez, necessita existir e ser contemporâneo aos liderados. O modelo determina o tipo de líder que uma comunidade segue. Assim, dar resposta à questão "que tipo de líder seguimos?" é, ao mesmo tempo, demonstrar o tipo de modelo que se imita, ou melhor, mostrar o íntimo de cada pessoa individual e social.

Com as diferenças supracitadas em mente, que, por sua vez, são pontuadas por Max Scheler em seu livro Modelos e líderes, dá-se luz a uma problemática importante, com a qual esse autor se preocupa: qual a importância de um modelo em uma unidade social? Tal questão é pertinente se for analisada a seguinte afirmação de Scheler no livro supracitado: “Os sistemas de valores, e mais ainda, os códigos e as legislações inspiradas [pelos modelos] naqueles sistemas, e aos quais a pessoa presta ou recusa obediência, têm sempre como ponto de partida os modelos que vivem em tal época" (SCHELER, 1998, p. 38).

Tal problemática deve ser olhada partindo do pressuposto de que há um modelo que exerce inspiração sobre o todo de uma unidade social, pois, para Scheler, há de constar um núcleo nessa unidade social, assim como há um núcleo na alma individual humana. Tal comparação é feita por Scheler, e ele conclui que o núcleo é constituído por uma minoria: em primeiro lugar, os modelos e, em segundo lugar, os líderes. Em uma unidade social há experiência e confronto de significados, tendo em vista a influência de seu núcleo, isto é, do modelo e, por isso, Scheler olha para essas unidades sociais e investiga as experiências éticas e religiosas de indivíduos, partindo do pressuposto da ideia sobre a poderosa e misteriosa força de influência do modelo.

Scheler pontua que o modelo é aquele que medeia a relação entre ser e dever-ser. Noutras palavras, há conexão entre consciência e campo de ação, mediada pelo modelo que se desvela em uma unidade social que, por sua vez, é apreendido pela percepção intencional dos indivíduos dessa mesma unidade. Com isso em mente, pode-se dizer que o núcleo da unidade social é primordial para definição do campo de ação.

Ainda em forma de introdução, cabe ressaltar que, para Max Scheler, no âmbito da ética, os valores são materializados na história. O responsável por 
permitir que tais valores sejam percebidos pelos indivíduos é o gênio-religioso moral. Faz parte da constituição desse gênio-religioso moral o caráter modelador de pessoas, pois o que rege a conexão de indivíduos e do gênioreligioso moral é o princípio de seguimento. Sobre esse princípio, Scheler, em seu livro $O$ Formalismo na ética e a ética material dos valores ${ }^{1}$, afirma: “[... o princípio de seguimento] é, antes de tudo, a única relação em que os valores morais positivos da pessoa A podem ser imediatamente decisivos para que surjam os mesmos valores pessoais em outro ser B; quer dizer, a relação do puro exemplo do bom.” (SCHELER, 1948, p. 387)2. Portanto, pode-se concluir juntamente com Scheler que esse sujeito, o gênio-religioso moral, que é o próprio valor em pessoa, traz consigo a exigência do dever-ser ideal para uma unidade social, quando seu valor é apreendido e vivido pelo indivíduo que o segue.

No âmbito da experiência religiosa, porém, só é possível apreender o Deus da consciência religiosa se existir conexão entre homem e Deus. Entre Deus e o mundo não há conexão direta, senão somente uma conexão mediada pelo homo religiosus. É o homo religiosus, ao mediar o nível divino (ser) e a comunidade (dever ser), o responsável por modelar a experiência religiosa de uma comunidade e, consequentemente, trazer o crescimento dos indivíduos. Segundo o que Scheler expõe em seu texto Problemas da religião: para uma renovação religiosa: “o Deus religioso é o Deus das pessoas santas e do povo de Deus, não o Deus do saber dos 'eruditos'. A fonte de toda verdade religiosa não é a discussão científica, mas a crença nos enunciados do homo religiosus, do 'santo."' (SCHELER, 2015, p. 172). O homem religioso vive em comunidades. É nas comunidades que a fonte da verdade religiosa se manifesta por intermédio da conexão de Deus no mundo, intermediada pelos enunciados do homo religiosus. A comunidade cresce na medida em que crê no enunciado do homem religioso.

À vista disso, tanto no âmbito da ética como na experiência religiosa, há uma pessoa valorosa que modela os indivíduos, isto é, um modelo-tipo. Os indivíduos, ao viverem o valor de pessoa do modelo, conscientemente, se

\footnotetext{
${ }^{1}$ Foi aderida a tradução do alemão para o espanhol desta obra de Max Scheler, realizada pela Revista do Occidente, pois não há tradução para o português. O livro foi traduzido em dois tomos, sendo que para este estudo foi selecionado o tomo II, intitulado Ética: nuevo ensayo de fundamentación de un personalismo ético. Desse modo, quando houver citações desta obra de Scheler será conservado o trecho original no espanhol, em nota de rodapé, enquanto que, no corpo do texto, a tradução para o português será nossa. Essa obra será citada, no texto, de modo abreviado $O$ Formalismo.

2 "Es, ante todo, la única relación en la que los valores morales positivos de la persona A pueden ser imediatamente decisivos para que surjan los mismos valores personales en outro ser B; quiere decir, la relación del puro ejemplo bueno".
} 
tornam pessoa dentro de uma unidade social. Assim sendo, escolhem suas lideranças e vivem uma experiência particular na história da comunidade em que cada indivíduo está inserido.

Ao olhar para o horizonte de uma comunidade é possível visualizar a presença de modelos e líderes ${ }^{3}$. Ao observar o agir dos membros de um grupo é factível notar alguns comportamentos e discursos que são condizentes com o modo como um modelo ou líder determina. A partir do olhar atento ao texto de uma comunidade, observando o discurso empregado e suas expressões idiomáticas, é possível visualizar uma abertura para interpretações, considerando o contexto dessa comunidade e o tipo de modelo que se tem. Desse modo, considerando tal possibilidade, este artigo intenta compreender a figura do modelo religioso inserido em uma comunidade particular, uma vez que, para Scheler, na construção de uma fenomenologia da essência da religião é preciso dar atenção aos modelos religiosos - os tipos essenciais diversos dos homines religiosi. A investigação dos modelos religiosos é importante, pois indica o modo como, a partir da palavra, há a manifestação do divino. Mas tal análise é possível quando se consideram as formas estruturais das comunidades, para quem, por intermédio do modelo religioso, a revelação se anuncia. Sobre isso, no texto Problemas da religião: para uma renovação religiosa, Scheler destaca:

A doutrina da essência das formas estruturais sociológicas das comunidades, para as quais a revelação se anuncia como revelação conjunta (diferentemente da iluminação individual e da graça) por meio de um "representante", precisa ser acolhida junto à natureza essencialmente social da religião na fenomenologia da essência da religião. (SCHELER, 2015, p. 211).

Dessa forma, o recorte deste artigo se limita à compreensão do mundo social de uma comunidade religiosa, assim como a presença do seu modelo religioso, na intenção de compreender a dimensão da sua experiência religiosa. Para tal análise, é selecionado o texto do Evangelho de Mateus; em especial, alguns versículos do Sermão da Montanha, pelo qual é possível verificar o progresso ético na formação do mundo social da comunidade, a saber, as Antíteses (Mt 5.17-48). A análise se faz possível na medida em que se reconhece o instrumental hermenêutico da correlação como possibilidade para análise fenomenológica, à luz de Scheler, do texto bíblico, sem deixar de reconhecer o

3 Essa análise foi melhor desenvolvida na dissertação de mestrado em Ciências da Religião defendida em setembro de 2016 na Pontifícia Universidade Católica de Campinas pela autora desse artigo e orientada pelo professor Dr. Newton Aquiles von Zuben, também autor do artigo. 
limite dos conceitos de cada realidade textual, mas considerando também os denominadores comuns.

Em busca de um correto entendimento sobre o Evangelho de Mateus e seu mundo, para esse estudo vale considerar dois autores: J. Andrew Overman e Juan Luis Segundo. Sendo, o primeiro, o autor do livro O Evangelho de Mateus e o Judaismo Formativo, que auxilia nos desenvolvimentos sobre o mundo da comunidade, sua constituição e compreensão da Lei; enquanto que a leitura de Segundo, considerando seu livro $O$ caso Mateus: os primórdios de uma ética judaico-cristã, contribui para apreender o modo como se deu a vivência da lei e sua importância.

O Evangelho de Mateus é um texto que pode ser analisado para compreensão dos aspectos da vida social de uma comunidade. Esse texto é a exemplificação dos eventos ocorridos depois do ano de 70 d.C, período marcado pela presença do Império Romano e a queda do Templo em Jerusalém, que significou a queda do centro religioso, cultural e político dos judeus. Com a queda do templo, os judeus são desafiados a retomar suas práticas políticas, econômicas, culturais, além das reuniões religiosas. Para as coalizões judaicas bem institucionalizadas, como a dos fariseus, foi fácil se reestruturar e se institucionalizar, uma vez que, antes mesmo do Templo desmoronar, os fariseus já desfrutavam da prática de reuniões em assembleias. Outras coalizões foram se formando e reestruturando seu modo de vida, como no caso da comunidade mateana, na qual os membros não eram bem institucionalizados como na coalizão dos Fariseus, mas assumiam posturas de liderança e oposição frente ao corpo principal político. Desse modo, há de constar um modelo que edifica todo o discurso e institucionaliza a comunidade mateana, a saber, Jesus Cristo.

Embora o texto faça menção ao período de 70 d.C, foi de fato escrito entre 80-9o d.C. Não se sabe ao certo quem o escreveu, mas o que se tem é a concretude das palavras, que desvelam uma realidade a ser interpretada na tríplice relação entre intérprete, texto e ouvinte. Portanto, ao correlacionar os conceitos que podem ser encontrados na realidade do texto bíblico e na realidade da construção fenomenológica scheleriana, é possível refletir sobre a existência de um modelo religioso e sua misteriosa força de influência na comunidade mateana, que é o objetivo deste artigo. Para compreensão desse empreendimento, passaremos por duas etapas: 1) compreender como o quadro conceitual scheleriano pode ser aplicado à comunidade mateana com o método da correlação; e 2) perceber a influência de Jesus, enquanto modelo, no progresso ético e na experiência religiosa. 


\section{A PERSPECTIVA FENOMENOLÓGICA DE MAX SCHELER}

Compreender que Max Scheler foi um filósofo que teve contato com os escritos de Edmund Husserl é importante e determinante para o próprio desenvolvimento intelectual desse homem, que é um dos nomes da corrente fenomenológica alemã. Deve-se considerar a questão que marcou a vida intelectual desse autor: o que é o homem?, questão esta que opera todo o desenvolvimento intelectual de Scheler.

Em sua fase fenomenológica (1916-1922), Scheler empreende o estudo e desenvolvimento de uma ética material, publicado no livro O Formalismo4, passando pelos estudos sobre modelos e líderes religiosos, publicados no livro Modelos e líderes 5 , até chegar aos escritos de 1922, publicados no livro Do eterno no homem 6 , intitulado Problemas da Religião: para uma renovação religiosa, no qual Scheler empreende a fenomenologia da essência religiosa. Tais obras são importantes para compreender o modo como Scheler pensava as organizações sociais, pois nesses três textos há um denominador comum: nas unidades sociais, para um progresso ético e/ou experiência religiosa, há um núcleo que exerce misteriosa força de influência, ou seja, seus modelos e líderes, como definido na introdução deste trabalho. Portanto, para o desenvolvimento dessa reflexão, vale considerar os argumentos de Scheler presentes nessas obras e apresentadas neste artigo. Afinal, o que Scheler tem a dizer sobre o progresso ético?

Para responder a essa questão, devem ser levados em consideração alguns aspectos sobre o modo como Scheler concebe a possibilidade de apreensão dos valores e o modo como eles se organizam. Para o filósofo, a razão não é o único elemento com o qual o homem consegue experiência, pois há fenômenos no mundo que não podem ser apreendidos pela razão - como os valores, por exemplo. Sobre isso, o filósofo, no livro O Formalismo diz: "há uma espécie de experiência cujos objetos são inteiramente inacessíveis à 'razão'; para esses objetos a razão é tão cega como pode ser o ouvido para as cores" (SCHELER, 1948, p. 26)7. Isso aponta para uma segunda característica que determina a atuação do homem no mundo, e tal determinação se dá pelos atos intencionais emocionais. Não se pode perder de vista a grandiosa influência que Blaise

\footnotetext{
4 Der Formalismus in der Ethik und die Materiale Wertethik.

5 Vorbilder und Führer.

6 Vom Ewigen im Menschen.

7 "Hay una especie de experiencia cuyos objetos son enteramente inaccesibles a la 'razón'; para esos objetos la razón es tan ciega como pueda ser lo el oído para los colores"
} 
Pascal exerceu sobre o pensamento de Scheler; pois assim como Pascal defende que “o coração tem razões que a própria razão desconhece”, Scheler defende que os valores só podem ser apreendidos pela percepção intencional emocional, porque só a razão não possui certa legalidade para compreender e acessar o cerne do valor manifestado no mundo da experiência.

Max Scheler trabalha na diferenciação de meros estados emocionais e percepção intencional emocional. Estados emocionais são variações de estados e condições. Por exemplo, posso sentir uma dor de cabeça, mas jamais posso inferir que o nível de dor que sinto é o mesmo das outras pessoas que já sentiram dor de cabeça. Ou, posso me compadecer da dor do outro, mas não posso sentir exatamente o que o outro sente. Ou seja, as condições e estados emocionais não podem ser intencionados, não são objetos do conhecimento total. No entanto, através da percepção intencional emocional é possível intencionar um objeto e, dessa forma, acessar sua essência. O que respalda essa diferenciação aqui descrita são as próprias palavras de Scheler, ao dizer: “[...] os estados emocionais radicalmente distintos do sentir (ou perceber sentimental), aqueles estados pertencem aos conteúdos e fenômenos, e este sentir, às funções da apreensão dos conteúdos e fenômenos" (SCHELER, 1948, p. 27) ${ }^{8}$. Sendo assim, a percepção sentimental é o que permite a consciente apreensão dos fenômenos primários - os valores. Além dessa determinação, Scheler apresenta mais duas características que conferem especificidade a esse perceber intencional sentimental, a saber, os atos de consciência emocionais e os estratos do sentir intencional. Tais características contemplam o modo como o homem pode apreender os valores no mundo.

Os atos de consciência são: o preferir e o preterir; e os atos emocionais são: o amor e o ódio. Os atos de consciência permitem a compreensão da totalidade de um valor, enquanto que os atos emocionais permitem a ampliação ou contração dos valores. Quando o homem prefere um determinado valor, isso significa que ele apreende a totalidade de conteúdo desse mesmo valor. Ao amar esse valor, o homem amplia esse conteúdo em seu ser. Mas, quando o homem pretere um valor, significa que ele não vive a totalidade do valor primeiro de uma hierarquia (o Ethos), e ao odiar esse valor, se vive a contração do conteúdo no ser do homem. De um lado, ao preferir e amar um valor, se intenciona seu conteúdo, e isso se dá na medida em que o homem vive seu núcleo espiritual de atos, dando atenção, desse modo, ao real conhecimento. Por outro lado, na medida em que o

8 “[...] los estados emocionales radicalmente distintos del sentir (o percibir sentimental), aquéllos pertencen a los contenidos y fenómenos, y éste, a las funciones de la aprehensión de contenidos y fenómenos”. 
homem pretere e odeia um valor, ressalta-se o fato do homem viver de acordo com seus atos sensíveis, fazendo com que não haja plena consciência e querer na realização dos valores no mundo - há somente uma obrigação inconsciente de seu real fundamento. A experiência ética é consciente na medida em que a concretização do valor do mundo é o resultado do preferir e amar humanos. Quando o homem pretere e odeia certo valor, significa que os valores se configuram como simples signos - atos automáticos com carência da plena consciência e realização do mesmo.

Mas, se os valores são concretizados no mundo de acordo como o homem prefere e ama, pretere e odeia, significa que os valores são relativos? Essa é uma questão que não cessa de ecoar nesta seção e que deve ser respondida. A ela será dado um vigoroso não, pois, para Scheler, os valores são objetivos. Para melhor explicar, o valor do sagrado é o mesmo para todos, mas o modo como o muçulmano vive as qualidades desse valor difere do modo como um judeu vive as qualidades desse mesmo valor. Isso não significa que há um valor de sagrado diferente para cada um, senão somente que há diferentes formas de viver sua respectiva qualidade na concretização no mundo. $\mathrm{O}$ que há é a relatividade do Ethos, que é a hierarquia na qual os valores se organizam. O Ethos da vida de um muçulmano é diferente do Ethos da vida de uma comunidade judaica. Isso se dá por duas razões: 1) em um primeiro momento porque a historicidade 9 toca o Ethos; 2) porque no desvelar dos valores superiores de um Ethos sempre há um gênio-religioso moral que, ao influenciar o perceber intencional de uma comunidade, faz com que os sujeitos que o seguem apreendam os valores superiores de uma hierarquia. Ora, mas quem é o gênio-religioso moral?

O gênio-religioso moral é o ponto de origem de todo o reino de valores superiores, pois é este gênio-religioso que determina as formas de preferência dos valores do Ethos, além de possibilitar um novo desvelar de valores. Nesse sentido, o gênio-religioso moral é o responsável pelo desvelamento dos valores superiores de um Ethos, mexendo assim com toda a estrutura de uma unidade social. Desse modo, vale rememorar as palavras de Scheler sobre o que vem a ser essa grandiosa influência que o gênio-religioso moral exerce: "É, por conseguinte, no gênio-religioso moral que se abre todo o reino de valores" (SCHELER, 1948, p. 83) ${ }^{10}$. Sendo assim, o campo de ação do indivíduo é influenciado pelo modo como o gênio-religioso moral toca a historicidade de um Ethos e, consequentemente, atuando sob a percepção intencional dos

9 A historicidade é importante para fundamentar que o Ethos não se adequa a uma realidade histórica, mas que já está inserido na estruturação dessa realidade. (SCHELER, 1948).

10 "Es, por conseguiente, en el genio-religioso moral donde se abre el reino de los valores". 
indivíduos desse campo de ação. Isso é o que caracteriza o progresso ético. Além disso, deve-se considerar que a relação entre gênio-religioso moral e indivíduos é ideal, e se dá a partir do ideal de seguimento. O ideal de seguimento pressupõe a apreensão do valor materializado na pessoa do gênio-religioso pelo indivíduo que idealmente o imita, fazendo, assim, com que a respectiva imitação, ou seguimento, seja consciente. Por isso, podemos dizer juntamente com Scheler que o princípio de seguimento é, "antes de tudo, a única relação na qual os valores morais positivos da pessoa A podem ser imediatamente decisivos para que surjam os mesmos valores pessoais em outro ser B; quer dizer, a relação do puro exemplo do bom". (SCHELER, 1948, p. 387). ${ }^{11}$ Considerando essa frase, pode-se afirmar que a relação ideal entre o ser da pessoa A e o ser da pessoa B permite o progresso ético e ideal, uma vez que essa relação confere a possibilidade de concretização dos valores no mundo social em que essa relação ideal do dever-ser ideal se dá. Desse modo, o ser da pessoa A é responsável pela regra de preferência e amor, preterição e ódio dos valores hierarquizados no Ethos da associação humana na qual os valores pessoais do ser da pessoa A manifestam-se no ser da pessoa B. O puro exemplo do bom é o ideal de seguimento.

Mas em quê essa reflexão desenvolvida por Max Scheler contribui para a análise de uma comunidade religiosa? Para compreender o valor da importância dessa reflexão, deve ser levado em consideração que todos os aspectos éticos de progresso e desenvolvimento em uma comunidade se dão no momento em que o gênio-religioso moral toca a historicidade dessa mesma comunidade e influencia no modo como cada indivíduo particular, que vive em comunidade, apreende os valores da sociedade. Tal constatação leva Scheler a desenvolver melhor sua teoria sobre modelos e líderes. Para ele, há uma hierarquia com os tipos de líder, mas há também uma hierarquia de modelos-tipo. Os modelostipo são mais influentes e importantes e vivem no núcleo de uma associação humana, que determina o discurso, a vivência, a cultura e as próprias leis e normas vividas pela comunidade. Portanto, olhar para o modelo-tipo de uma comunidade aponta para os significados construídos em comunidade. Com isso em mente, levanta-se uma questão importante, considerando o objetivo deste artigo: quem é o modelo-tipo da comunidade mateana e como esse modelo determinou o cumprimento da Lei dessa mesma comunidade?

11 "Es, ante todo, la única relación en la que los valores morales positivos de la persona A pueden ser inmediatemente decisivos para que surjan los mismos valores personales en otro ser B; quiere decirse, la relación del puro ejemplo bueno". 


\section{O CUMPRIMENTO DA LEI NA COMUNIDADE MATEANA}

Para dar conta de uma resposta à questão levantada na seção anterior, devem ser levados em conta alguns aspectos característicos dessa comunidade. Tais aspectos serão analisados à luz de dois autores diferentes, a saber: J. Andrew Overman, considerando seu livro O evangelho de Mateus e o judaísmo formativo, e o autor Juan Luiz Segundo, que realiza uma análise éticoantropológica do evangelho de Mateus em seu livro O caso Mateus: os primórdios de uma ética judaico-cristã.

No contexto da hipotética comunidade mateana havia características que permitiam a fundamentação do discurso e da oposição ao corpo principal - a centralidade da Lei. Ora, não basta saber qual é a Lei, mas importa agir em conformidade com a Lei, ou seja, não basta a Lei estar no nível do ser, mas deve habitar o nível do dever-ser. Sobre isso vale rememorar as palavras de J. Andrew Overman quando escreve que: "o essencial é que o cumprimento da Lei é determinado pela interpretação que se faz dela” (OVERMAN, 1997, p. 93). Além disso, tal característica possui relação direta com alguns versículos específicos do Evangelho de Mateus, a saber, O Sermão sobre a Montanha (Mt 5-7), em especial, os seguintes versículos:

Não penseis que vim revogar a Lei ou os Profetas. Não vim revogá-los, mas darlhes o pleno cumprimento, porque em verdade vos digo que, até que passem o céu e a terra, não será omitido nem um só i, uma só vírgula da Lei, sem que tudo seja realizado. Aquele, portanto, que violar um só desses menores mandamentos e ensinar os homens a fazerem o mesmo, será chamado o menor no Reino dos Céus. Aquele, porém, que os praticar e os ensinar, esse será chamado grande no Reino dos Céus. (Mt 5.17-19).

Esses versículos fundamentam os argumentos do próprio estudioso Overman, pois demonstra que a Lei é de fundamental importância para centralizar os significados construídos, interpretados e vividos pela comunidade mateana, em vista da institucionalização da própria comunidade. Nesses versículos, segundo Overman, é defendida a validade eterna da Lei e, sobre isso, o autor afirma: "Mateus acredita que tanto Jesus como sua comunidade, que age de acordo com os ensinamentos de Jesus, são seguidores e cumpridores da Lei." (OVERMAN, 1997, p. 93).

Consideramos ainda, sobre a natureza da centralidade da Lei para a comunidade, os argumentos de Juan Luiz Segundo, em seu livro O caso Mateus. Segundo, em um de seus capítulos, inicia sua reflexão com a seguinte questão: cumprimento de toda a Lei ou outra Lei? Ora, é preciso considerar essa 
indagação, pois, a partir dela, pode-se entender melhor o que significa de fato cumprir a Lei para essa comunidade. Afinal, qual Lei deve ser cumprida a ponto dos indivíduos dessa comunidade serem chamados grandes no Reino dos Céus?

Para responder tal questão, é preciso relembrar que os valores para os indivíduos da comunidade mateana não ficam isolados no nível do ser, mas se materializam no âmbito do dever-ser. Não basta saber ou só interpretar a Lei, é preciso vivê-la. Portanto, aqui se pergunta: quem é o responsável por permitir que a Lei não seja somente entendida, senão praticada e vivenciada verdadeiramente? Jesus Cristo! A pessoa que intermedeia a relação entre ser e dever-ser é Jesus Cristo. A autoridade de Jesus para essa comunidade é evidente ao perceber a técnica de atualização da perícope. O autor do texto, segundo J. Andrew Overman, bebeu das profecias de Isaías e as alinhou aos eventos e fatos da vida de Jesus, fazendo com que Jesus fosse a concretização do que o profeta havia previsto. Sobre essa característica, vale rever a descrição apresentada por Overman:

O termo "citações de cumprimento" refere-se especificamente à utilização de uma profecia da Bíblia hebraica por Mateus com a afirmação de que um determinado evento aconteceu "para cumprir" algo que foi previsto por um profeta. Em Mateus, mais da metade das citações de cumprimento vêm de Isaías. (OVERMAN, 1997, p. 80).

Seguir Jesus é viver a realização de uma profecia. A essa técnica de atualização se dá o nome de citação de cumprimento, na qual algo é citado para justificar o cumprimento de uma profecia e, assim, é dada autoridade à pessoa de Jesus Cristo, que passa a ser o núcleo valorativo e institucionalizante da comunidade.

Mas, retornando à questão de Juan Luiz Segundo, adiantada no parágrafo anterior: cumprimento de toda a Lei ou outra Lei? Responder a essa questão olhando somente para Overman nos permite dizer que é o cumprimento de toda a Lei, mas o cumprimento dado à luz da interpretação própria da assembleia mateana. A Lei é a mesma para todas as comunidades do momento, mas o palco do debate se dá no âmbito da interpretação das virtudes reconhecidas no Judaísmo. A assembleia mateana tinha a preocupação de conservar perfeccionisticamente as virtudes judaicas; contudo, tal conservação se dá à luz da correta interpretação que, por sua vez, só a comunidade mateana possui. Para os mestres e aqueles conscientemente inseridos na comunidade mateana, sua própria interpretação permite o cumprimento de toda a Lei. Todavia, deve ser dada atenção a uma constatação feita por Segundo, a saber: 
As Bem-Aventuranças, tal como Mateus apresenta, quase não têm qualquer originalidade. Praticamente trata-se de virtudes reconhecidas como tais no Judaísmo. Nelas, nada existe que já não esteja - e praticamente com as mesmas palavras - no Antigo Testamento. (SEGUNDO, 1997, p. 77).

Com essa constatação em mente, deve-se considerar, juntamente com Juan Luiz Segundo, que quem quiser compreender profundamente o cerne da interpretação e progresso ético, assim como o palco do debate desse momento entre a comunidade mateana e as autoridades, deve levar em consideração as Antíteses (Mt 5.17-48). Mas, por que as Antíteses? Ora, as Antíteses é o texto no qual se vê, a cada citação, a intenção de elevação à plenitude da virtude judaica, das quais Segundo diz: "[... o lugar] onde, a cada citação de um preceito da antiga Lei, Jesus teria oposto um 'mas eu vos digo (...)', e isso para levar à sua plenitude a religião judaica." (SEGUNDO, 1997, p. 78). Mas, considerando o que Segundo tem a dizer sobre a elevação da Lei ao lado de Overman, que mostra a importância da centralidade da Lei, o que pode ser concluído?

Até o momento, pode-se dizer que Jesus Cristo se torna o núcleo da comunidade na medida em que ele é apresentado como aquele que veio para cumprir as antigas profecias. Tal apresentação é realizada pela técnica discursiva da citação de cumprimento. Portanto, para compreender mais propriamente a influência desse núcleo é preciso olhar para a mensagem que traz o cerne da interpretação da Lei, que são as Antíteses, no qual se apresenta algum princípio judaico que já havia sido afirmado, mas com um "mas eu vos digo (...)" para elevar o sentido desse preceito. Desse modo, pode-se dizer que o preceito da Lei é elevado a partir de Jesus Cristo. Os membros da comunidade mateana vivenciam a prática da Lei à luz dessa elevação fundamentada pela autoridade dada à pessoa de Jesus. Assim sendo, toda a linguagem da comunidade mateana se desenvolve tendo Jesus Cristo como a personalidade que eleva a Lei e conserva a aliança divina.

Em uma perspectiva social, a comunidade mateana desenvolveu discursos para enfatizar que aqueles que viviam a lei à luz de Jesus eram os verdadeiros herdeiros do Reino dos Céus, enquanto que os Fariseus, por exemplo, eram aqueles que herdariam o direito de estar na geena de fogo. O fundamento da lei judaica era o mesmo para a coalização dos Fariseus e para a comunidade mateana. Não existia a opção de ignorar a lei, e sobre isso Andrew Overman afirma: 
A Lei judaica aparecia como uma questão importante e essencial na luta entre a comunidade de Mateus e a oposição. Só isso já nos diz muito sobre o ambiente e a origem do Evangelho e sobre a identidade dos oponentes de Mateus. Ambas as partes tinham a Lei em alta conta. A Lei em si não era de forma alguma opcional. Ambos os grupos a reivindicavam e acusavam o outro de distorcê-las. Ela servia como meio de desacreditar o oponente e afirmar sua própria posição. (OVERMAN, 1997, p.95)

O núcleo da lei era o mesmo para as coalizões. Mas, a partir de interpretações para desacreditar e lançar denúncia à oposição, bem como o desenvolvimento de discursos para sublinhar a posição da própria comunidade, demonstra que as qualidades de vivência da lei eram diferentes para cada um. Ora, mas o que o filósofo Max Scheler tem a contribuir para essa análise aqui adiantada?

\section{O PROGRESSO ÉTICO}

Em vista da continuidade dessa reflexão, se intenta agora responder à questão da seção anterior. Mas, antes disso, é necessário reconhecer, à luz de J. Andrew Overman, que todas as recomendações e orientações dirigidas aos membros do grupo mateano tinham o objetivo de firmar o alicerce valorativo e institucional do grupo, assim como lançar denúncias e assumir posturas de oposição. A prova dessa postura é o próprio texto bíblico, exemplificado através do seguinte versículo:

E quando orardes, não sejais como os hipócritas, porque eles gostam de fazer oração pondo-se em pé nas sinagogas e nas esquinas, a fim de serem vistos pelos homens. Em verdade vos digo: já receberam sua recompensa. Tu, porém, quando orares, entra no teu quarto e, fechando a tua porta, ora a teu Pai que está lá, no segredo; e teu pai, que vê no segredo, te recompensará. (Mt 6.5-6).

O trecho acima é a exemplificação de uma orientação ritualística. A orientação demonstra que para os membros da comunidade a recompensa existe, desde que entre em teu quarto e, fechando tua porta, faça tuas orações em segredo. Tal orientação acentua o modo como se entende um dos muitos aspectos das práticas religiosas. Mas, é lançada uma denúncia também, a saber: não sejais como os hipócritas! Ora, quem são os hipócritas? É muito provável que sejam aqueles que não seguem as orientações ao mesmo modo da comunidade mateana. Enquanto os mestres desse grupo orientavam os membros e desenvolviam modos de preservação e institucionalização das práticas da comunidade, é lançada uma acusação àqueles que oram a fim de serem vistos, isto é, a oposição. 
Nesse sentido, os desdobramentos do pensamento ético de Max Scheler, desenvolvido em $O$ Formalismo, contribuem para a compreensão desse comportamento. Max Scheler defende que os valores são objetivos e fenômenos primários manifestados no campo de ação humano. As pessoas os percebem a partir do sentir intencional desses mesmos valores. As intuições das pessoas podem ser influenciadas pelo tipo de modelo que fundamenta o núcleo valorativo do campo de ação ao qual certo grupo pertence. Se há diversas unidades sociais, isto é, diferentes grupos, como é o caso da realidade histórica da assembleia mateana, há de constar modos diferentes de perceber intencionalmente (o sentir intencional) dos valores. Tal diferença não influencia o núcleo objetivo do fenômeno primário: o valor. Mas, influencia no modo como tal valor é vivido na história; noutras palavras, no modo como cada grupo, com suas particularidades, vive e acessa a qualidade desses valores.

Considerando o que foi explicitado brevemente nos parágrafos anteriores, há de constar pontos em comum entre o pensamento scheleriano e a realidade da comunidade mateana, e é partindo dos denominadores comuns dessas realidades textuais que se funda essa análise. A lei judaica é fundamentada por um valor objetivo, o denominador comum para todas as coalizões que se afirmam como judaicas. O modo como a comunidade mateana interpretava a lei era fundamentado por esse valor objetivo, mas, além disso, era respaldado pelo modelo religioso apreendido. Jesus Cristo era o núcleo valorativo de todo o discurso desenvolvido, assim como das estratégias para institucionalização da comunidade.

$\mathrm{O}$ aspecto ético da conduta da comunidade mostra o modo como os significados no mundo social são construídos e vivenciados. Desse modo, se tem em mente que a interpretação da Lei permite a relatividade do Ethos e não a relatividade dos valores (virtudes fundamentais do judaísmo). Se Jesus diz um "mas eu vos digo [...]" tal afirmação preza pela influência na percepção intencional dos indivíduos dessa comunidade. Assim sendo, se por um segundo for analisada uma das Antíteses, ao modo de Juan Luiz Segundo, pode ser visualizado que além de tentar conservar a Lei, se diz algo sobre essa Lei que reflete nas ações concretas vivenciadas. Como exemplo, vamos analisar dois versículos de uma das seis Antíteses:

Ouviste o que foi dito aos antigos: Não matarás; aquele que matar terá de responder no tribunal. Eu, porém, vos digo: todo aquele que se encolerizar contra seu irmão, terá de responder no tribunal; aquele que chamar ao seu irmão "Cretino!" estará sujeito ao julgamento do Sinédrio; aquele que lhe chamar "renegado" terá de responder na geena de fogo. (Mt 5.21-22). 
De acordo com o que Juan Luiz Segundo apresenta em seu livro, o "acréscimo" fundamentado por Jesus Cristo faz com que o pecado não seja somente o ato de matar, mas aumenta-se a gravidade do ato. Ou seja, conservase o aspecto do que havia dito e lhe oferece uma interpretação, que vem para dar o pleno cumprimento da Lei. Desse modo, os membros da comunidade mateana, a partir da influência sob a percepção intencional dos indivíduos fundamentado pelo núcleo valorativo que é Jesus Cristo, passam a compreender que o agir de modo negligente com outro membro da comunidade pode trazer penalidades. Sobre isso, Juan Luiz Segundo afirma: "aumenta-se a gravidade de atitudes hostis para com o irmão.” (SEGUNDO, 1997, p. 82). E, assim se sucede, também, com as outras Antíteses, isto é, há em toda citação um "mas eu, porém, vos digo [...]" e o que segue é a interpretação que possui como fundamento nuclear e valorativo o modelo, que é Jesus Cristo. Sendo assim, à luz de Jesus, a comunidade compreende que não se deve matar e/ou injuriar o irmão.

Em uma perspectiva scheleriana, considerando o progresso ético e o exemplo dado à luz de Segundo, pode-se dizer que Jesus Cristo é o gênioreligioso moral que traz essa noção diferente das ações hostis para com o irmão. O “mas eu, porém, vos digo [...]" é a prova da possível influência ou tentativa de influência sob a percepção intencional dos indivíduos. A influência se dá através da palavra fundamentada pelo gênio-religioso. Mas, o que isso tem a contribuir para a análise fenomenológica da essência da religião?

Para responder a essa pergunta é preciso rememorar que Scheler, em seu texto Problemas da religião, afirma que o papel da fenomenologia da essência da religião é conhecer os tipos essenciais de homens religiosos, o modelo religioso, a partir da estrutura social de uma comunidade. Essa análise se faz importante na medida em que o modo pelo qual o divino se manifesta na comunidade se dá através da palavra revelada pelo homo religiosus. Scheler diz que: "por meio da palavra, contudo, o divino só consegue se manifestar, na medida em que e até o ponto em que ele mesmo é pessoa e na medida em que e até o ponto em que ele se revela em pessoas." (SCHELER, 2015, p. 210). Nesse sentido, a compreensão sobre o que vem a ser modelo religioso e líder religioso se faz importante, e tal distinção é melhor visualizada no texto Modelos $e$ Líderes de Scheler. Justamente esta distinção nos permite dizer que Jesus Cristo é o modelo religioso e o valor de pessoa encarnado em pessoa que é apresentado pelos membros da comunidade mateana, ou seja, pelo líder religioso da comunidade. 
Tal conclusão é possível porque existe a preocupação em analisar o mundo social da comunidade mateana. Portanto, olhar para Jesus Cristo contribui para melhor discernimento dos significados que foram construídos na comunidade mateana. Jesus Cristo é o modelo que não precisa existir e ser contemporâneo aos seus imitadores. $\mathrm{O}$ discurso à luz de seu valor de pessoa o faz ser possível na comunidade. Jesus Cristo não sabe que é modelo e não almeja tal tarefa. Mas, ele influencia os atos de amor e de preferir da consciência humana. Desse modo, aos olhos de Scheler, se a comunidade mateana imitou Jesus, tal imitação não foi um mero "Jesus me obriga", noutras palavras, uma obrigação inconsciente. Mas, a imitação se deu à luz do puro exemplo do bom, ou seja, do princípio de seguimento. Imitar Jesus significa conhecer as razões e fundamentos que justificam o seguimento. Idealmente se imita Jesus na medida em que a prática da Lei é fundada na interpretação da própria comunidade mateana.

Os mestres da comunidade são os homens religiosos que, ao proferirem o discurso que, por sua vez, é valorativamente fundamentado por Jesus, medeia a relação de Deus no mundo. Portanto, os indivíduos da comunidade apreendem o fenômeno religioso no mundo, na medida em que os mestres discursivamente mostram a importância de cumprir a Lei à luz de Cristo.

\section{CONSIDERAÇÕES FINAIS}

Olhar atentamente para o discurso desenvolvido no Evangelho de Mateus, em especial, as Antíteses (Mt 5.17-48), correlacionado aos aspectos fenomenológicos de Scheler, permite dizer que através desses versículos específicos é possível visualizar uma nova maneira de compreender o modo correto de cumprir a Lei. A elevação da Lei judaica é dada pelo "acréscimo" de Jesus que influencia a percepção intencional dos sujeitos da comunidade. Além disso, é alicerçado o palco das discussões interpretativas entre a comunidade mateana e as autoridades desse momento.

Compreender o conceito de modelo religioso permite a análise fenomenológica do progresso ético da comunidade mateana, além de ser um dos pontos de partida para a estruturação da fenomenologia da essência da religião, como Scheler concebe. Desse modo, apontar que Jesus Cristo é o modelo religioso é o mesmo que dizer, parafraseando Scheler, que Jesus Cristo é “o valor encarnado numa pessoa, com rosto que fica pairando na frente do espírito da pessoa ou do grupo", e de tal modo o espírito da comunidade mateana "vai tornando seus traços e transformando-se que seu próprio ser, sua vida, seus atos, consciente ou inconscientemente, vão se conformando tanto com o modelo 
[Jesus Cristo] que o espírito diz sim e se sente aprovado." (SCHELER, 1998, p. 36). Mas, o que confere autoridade à pessoa de Jesus Cristo? Essa questão pode ser respondida levando em consideração as citações de cumprimento, pois através delas são alinhados eventos da vida de Jesus às antigas profecias da tradição judaica, de modo que se entende que cumprir e viver à luz de Cristo é o mesmo que cumprir as antigas profecias, de acordo com o que Overman nos demonstra.

A institucionalização da comunidade se deu à luz do modelo religioso que é Jesus Cristo. Essa afirmação é respaldada pela própria caracterização que Scheler dá à força de influência do modelo religioso, a saber, "os sistemas de valores, e mais ainda, os códigos e as legislações inspiradas naqueles sistemas, e aos quais a pessoa presta ou recusa obediência, têm sempre como ponto de partida os modelos que vivem em tal época, as pessoas que encarnam animadamente esses valores." (SCHELER, 1998, p. 38). Tal característica pode ser vista na comunidade mateana na análise das Antíteses (Mt 5.17-48). O "acréscimo" dado a cada Antítese parte do modelo religioso: Jesus Cristo. Nesse sentido, Jesus Cristo é o princípio que institui a assembléia mateana conferida através do progresso ético.

\section{REFERÊNCIAS}

BÍBLIA. A Bíblia de Jerusalém. São Paulo: Paulus, 1985.

OVERMAN, J. Andrew. O evangelho de Mateus e o judaísmo formativo: o mundo social da comunidade de Mateus. São Paulo, SP: Edições Loyola, 1997.

SCHELER, Max. Do eterno no homem. Petrópolis: Vozes, 2015.

De lo eterno en el hombre. Madri: Encuentro, 2007.

Ética: nuevo ensayo de fundamentación de un personalismo ético. Tomo II.

Buenos Aires: Revista de Occidente Argentina, 1948.

Modelos e líderes. Curitiba: Campagnant, 1998.

Problemas da religião: para uma renovação religiosa. IN: SCHELER, MAX. Do

eterno no homem. Petrópolis: Vozes, 2015.

SEGUNDO, Juan Luiz. O caso Mateus: os primórdios de uma ética judaico-cristã.

São Paulo: Paulinas, 1997. 